\title{
Antología de la literatura fantástica de 1940
}

\author{
Anna Gargatagli • \\ Universidad Autónoma de Barcelona
}

\section{Resumen}

La Antología de la literatura fantástica de Borges, Bioy y Silvina Ocampo estableció un canon formal para la literatura argentina futura. En este artículo se analizan el origen, la edición, las traducciones y la función literaria del repertorio. En 1940, año de la primera edición, Borges era autor de algunos de sus relatos más memorables (entre ellos «Tlön, Uqbar, Orbis Tertius", incluido en la Antología); Bioy había publicado La invención de Morel, influyente entonces y todavía; Silvina Ocampo escribiría más tarde algunos de los relatos más inquietantes de la literatura argentina cuyas huellas estaban entrelíneas en Viaje Olvidado que había aparecido en 1937. ¿Por qué se hizo este libro?

\section{Palabras clave:}

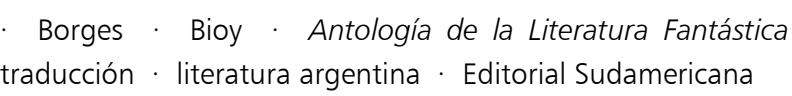

\begin{abstract}
The Book of Fantasy (Antologia de la Literatura Fantástica) by Borges, Bioy and Silvina Ocampo established a formal canon for the future Argentinean literature. In this article, the origin, the edition, the translations and the repertoire's literary role are analyzed. In 1940, year of the first edition, Borges was the author of some of his most memorable tales (among them "Tlön, Uqbar, Orbis Tertius», included in the anthology); Bioy had published The Invention of Morel, influential then and even today; Silvina Ocampo would then write some of the most disturbing stories of the Argentinean literature which marks were interlinear in Forgotten Journey that had appeared in 1937. Why was this book made?
\end{abstract}

\section{Key words:}

The Book of Fantasy (Antología de la Literatura Fantástica) Borges · Bioy Casares · Silvina Ocampo

\footnotetext{
- Profesora emérita de la Universidad Autónoma de Barcelona. Autora y coautora de artículos y libros sobre crítica literaria y traducción, entre ellos: La traducción en América Latina (Buenos Aires, Paidós/ Typa, 2012), Escrituras de la traducción hispánica (Universidad Austral de Chile, 2009), École, culture et nation (Université Paris X, 2005), Los traductores en la historia (Antioquía, 2005/Editions Unesco), El tabaco que fumaba Plinio (con Nora Catelli, Serbal, 1998), Borges y la traducción (UAB, 1993). Codirige 1611. Revista de historia de la traducción.
} 
La Antología de la literatura fantástica de Borges, Bioy y Silvina Ocampo hubiera podido llamarse revelación de lo fantástico (o algo semejante que significara descubrimiento o invención) porque con ella la literatura fantástica dejó de ser concebida como subgénero o género menor para verse como uno los modos privilegiados de la ficción.

No existía esta definición en 1940, cuando se publicó el libro. Sus consecuencias fueron la clasificación francesa de Pierre-Georges Castex (1951) o las reflexiones sobre lo fantástico de Roger Caillois (1958), Louis Vax (1960) o Tzvetan Todorov (1970). De hecho, la exposición más extensa y citada, la de Todorov, está contenida en una frase del prólogo de Bioy a la Antología:

algunos autores descubrieron la conveniencia de hacer que en un mundo plenamente creíble sucediera un solo hecho increíble; que en vidas consuetudinarias y domésticas, como las del lector, sucediera el fantasma. Por contraste, el efecto resultaba más fuerte. (Borges, Bioy, Ocampo, 1940:9)

La transformación de una modalidad genérica en una estrategia narrativa — para escribir un relato fantástico se debe tener un argumento original, concebir una trama visible (tranquilizadora) que sostenga la trama invisible (inquietante) y darle al lector el protagonismo de la revelación — supuso, además, que historias heredadas del pasado se pudieran convertir en un objeto literario con un valor simbólico hasta entonces desconocido. Tampoco existía este prestigio antes.

Dos empresas más o menos contemporáneas de la Antología señalan su novedad. En el escenario inglés, el género fantástico tenía borrosas ramificaciones, como las que figuran en las obras del eclesiástico, controvertido y excéntrico Montague Summers que acumulaba apariciones, brujas, hombres lobo, demonología, satanismo, nigromancia, terror gótico, adivinación, muertos vivientes, hechicería, vudú, posesión, ocultismo, perdición y destino fatal en sólo uno de sus repertorios: The Supernatural Omnibus (London, Gollancz, 1931). Las obras siguientes de Summers incluían otras posibilidades.

En el escenario francés, la Antología del humor negro de André Breton, editada también en 1940 (aunque distribuida al terminar la ocupación alemana en 1944), supuso una operación diferente. Breton dio un significado nuevo al concepto de humour noir reuniendo fragmentos y relatos con argumentos transgresores — nada transgresores en la forma literaria - que, leídos ahora, resultan una perecedera extensión del surrealismo, el testimonio de la forma francesa de las vanguardias. Si Summers buscaba los autores dentro de la tradición de su lengua, la Antología del humor negro de Breton fue una cuestión casi solo francesa porque - con dos o tres excepciones- los antologados extranjeros fueron parte de la tradición artística de Francia: Edgar Alllan Poe, Pablo Picasso, Alberto Savinio, Salvador Dalí. A diferencia de Picasso, Savinio (Andrea de Chirico) y Salvador Dalí que vivieron muchos o algunos ańos en París, Poe no, pero traducido por Charles Baudelaire quedó incorporado a la tradición francesa y también europea. ${ }^{1}$

La obra de Breton se diría que pertenece a Breton y a la tradición surrealista de la literatura francesa que, en cierto modo, también singulariza a Breton.

Impersonal, subrayadamente impersonal, la Antología de Borges, Bioy y Silvina Ocampo reunía un repertorio de autores ingleses, franceses, alemanes, italianos, 
latinos, españoles, árabes, chinos y argentinos que se encadenaban en una lectura que producía efectos casi metonímicos por la contigüidad.

El borramiento de los autores — el lector lee a Max Beerbohm, a Petronio, a Kakfa no a Borges, Bioy o Silvina Ocampo- también se relaciona con «dar al mundo algo nuevo» como se dice de Enoch Soames, protagonista del relato que abría el libro original y que parece un programa artístico de lo que la Antología representa. Lo nuevo era la posibilidad de un aprendizaje ofrecido por «creadores de cultura, auctores capaces de imponer su auctoritas en materia artística» (Bourdieu). Imposición impersonal porque en la lejana jerarquía medieval de la escritura (y en 1940) el auctor era el espíritu inspirador que dejaba al scriptor, compilator o commentator la realización material de la obra. Escritores, compiladores o comentadores que ofrecían al lector una moderna Bibliotheca Musarum con un repertorio de argumentos y, más importante todavía, con leyes para utilizarlos:

No debe confundirse la posibilidad de un código general y permanente, con la posibilidad de leyes. Tal vez la Poética y la Retórica de Aristóteles no sean posibles, pero las leyes existen; escribir es, continuamente, descubrirlas o fracasar. Si estudiamos la sorpresa como efecto literario, o los argumentos, veremos cómo la literatura va transformando a los lectores y, en consecuencia, cómo éstos exigen una continua transformación de la literatura. Pedimos leyes para el cuento fantástico; pero ya veremos que no hay un tipo, sino muchos, de cuentos fantásticos. Habrá que indagar las leyes generales para cada tipo de cuento y las leyes especiales para cada cuento. El escritor deberá, pues, considerar su trabajo como un problema que puede resolverse, en parte, por las leyes generales y preestablecidas, $y$, en parte, por leyes especiales que él debe descubrir y acatar. (Borges, Bioy, Ocampo, 1940:8)

Los lectores de este libro — no concebidos como público «indiferenciado, impersonal o anónimo" (Bourdieu) ni como masa de compradores — fueron vislumbrados como escritores. Escritores que, como pensaba Valéry, serían creadores de su propio libro.

\section{La edición}

La versión original de la Antología de la literatura fantástica de 1940 apareció en una colección, «Laberinto», que sólo tuvo dos títulos. La tapa tenía, como fondo, una pared de ladrillos grises con un ángel desnudo y azul cuyas alas sostenían dos columnas y uno de cuyos pies se apoyaba en la leyenda "Colección Laberinto». Letras rojas enunciaban el título del libro, en negro los autores y el nombre de la editorial. No hubiera resultado rara la inclusión de un par de calaveras y algún fantasma cubierto con una sábana.

Con ligereza podría opinarse que esos detalles correspondían al modo como la editorial entendía la literatura fantástica. Nos equivocaríamos. En el otro volumen de la colección «Laberinto»: Antología poética argentina (1941), también de Jorge Luis Borges, Adolfo Bioy Casares y Silvina Ocampo, se veía la misma pared, el mismo ángel e idénticas columnas aunque todo de color marrón.

El interior del volumen de 1940 tenía una impresión confusa. Los textos seleccionados eran de diferente extensión y en la organización tipográfica los fragmentos 
muy breves, sin títulos, se situaban en los blancos que dejaban los finales de los cuentos largos. Esa confusión contribuía, sin embargo, a que la Antología se leyera como un volumen continuo. En las sucesivas ediciones - que siguieron en el futuro el orden alfabético de los autores_ las asociaciones por contigüidad desaparecieron.

La obra fue publicada por la «Sudamericana», como la llamaba Victoria Ocampo, fundadora de la editorial en 1939:

María de Maetzu, diez años después de nacer mi editorial [se refiere a la editorial Sur] (...) me puso en contacto con un financista catalán interesado en organizar una editorial. Era la época de la guerra civil española. De inmediato — debido al antitotalitarismo franquista de Sur - surgieron dificultades políticas. Sur tenía fama de comunistoide entre los conservadores (entre la oligarquía) y de fascista entre las izquierdas. Tratamos de llegar a una convivencia pacífica con el financista catalán. Dijimos: "Let's agree to differ». Nos empeñamos en establecer una línea de demarcación. Hasta allí podríamos llegar nosotros, hasta otro allí los nuevos socios. Con este espíritu se fundó la Editorial Sudamericana (a la que pasó el fondo editorial de Sur). Pero a poco andar las incompatibilidades surgieron, violentas. Me separé de la Sudamericana que quedó fundada y siguió prosperando, sobre todo cuando llegó Antonio López Llausàs. Entre tanto, las cuestiones políticas fueron apaciguándose «en cierta medida». Pero ya era tarde para impedir nuestro divorcio. Y tendrían que pasar muchos ańos antes de volver yo a esa gran editorial de cuya fundación fui, por lo menos, el principal pretexto. El nombre de Sudamericana nació de la imposibilidad de seguir llamando Sur a la Editorial porque esta palabra tenía un dejo revolucionario e iconoclasta... Los libros de Mounier y Maritain publicados por Sur no recibieron el imprimatur de la nueva editorial. (Ocampo, 1966:17)

Las relaciones de Victoria Ocampo con la editorial Sudamericana siguieron un curso que desconocemos. Algún tiempo más tarde, Roger Caillois le comentaba en una carta: «Quise plantear la cuestión [la edición de su trabajo sobre el género policial] a López Llausàs. Pero deseaba preguntarte en qué términos habías quedado finalmente con Sudamericana. Pues no quisiera "traicionarte". Comprendes lo que pretendo decir». (Ocampo, 1999:112)

Aunque Victoria Ocampo abandonó la empresa, los libros (y las traducciones) de la editorial Sur que se incorporaron a la Sudamericana siguieron vendiéndose hasta hoy y casi se podría decir que es la única sección del inmenso catálogo que siguió viva.

Además de Victoria Ocampo los primeros accionistas de Sudamericana fueron: Oliverio Girondo, Jacobo Saslavsky, Andrés Bausili, Luis Duhau, Enrique García Mérou, Alfredo González Garaño, Alejandro Menéndez Behety, Carlos Mayer, (¿?) Sáenz, Emilio Ravignani, Antonio Santamarina y Alejandro Shaw. ${ }^{2}$ También participó Rafael Vehils, el financista catalán al que mencionaba la fundadora de Sur. La llegada de Antonio López Llausàs, primero director después único propietario, debió coincidir con los preliminares de la Antología. López Llausàs había sido fundador en Barcelona de la librería y editorial Catalònia, muy relevante en el campo de la cultura catalana, y había participado del asociacionismo empresarial que culminó con la creación de la Cámara Oficial del Libro de Barcelona en 1922 y los proyectos exportadores a América. Sudamericana tuvo como gerente a Julián Urgoiti, llegado a la Argentina en 1928 como directivo de Espasa-Calpe, y, como asesor literario, desde 1945, al escritor y traductor catalán Cèsar August Jordana. ${ }^{3}$

Tanto López como Urgoiti conocían bien el modelo editorial español, una industria que desde el siglo XIX adoptó una forma expansiva y exportadora, destinada 
a la "conquista de los mercados americanos». La instalación en Buenos Aires de filiales de editoriales españolas (Aguilar, Juventud, Labor, Gustavo Gili), la fundación de Losada (1938) y la dirección también española de Emecé y Sudamericana modificaron el mundo de la edición en la Argentina que había tenido su (propio) y notable desarrollo en las primeras décadas del siglo Xx.

Gestionada por López, Sudamericana compró otras editoriales nacionales y fundó dos filiales: Edhasa (1946) en Barcelona y Hermes (1947) en México. La Antología de la literatura fantástica se exportó a España en 1945, atravesó todos los requisitos de la censura fascista (que la aprobó) y 1000 ejemplares (casi una edición entera de la época) se vendieron sin problemas.

No existe ninguna confirmación de que la exportación de la Antología - y sobre todo el paso por la censura - hubiera sido consultado con los autores o se hubiera tenido su consentimiento. El trámite ante las autoridades censorias (todavía la Vicesecretaría de Educación Popular de la fet de las Jons, abreviatura de Falange Española Tradicionalista y de las Juntas de Ofensiva Nacional Sindicalista, que dirigía la Dirección Nacional de Propaganda, a cargo entonces de la Sección Censura) fue muy rápido (no más de 15 días) lo que sugiere, según las costumbres, que quienes hacían la solicitud (los socios de López Llausàs en Barcelona) tenían buena relación con las autoridades. El relato de Victoria Ocampo es bastante elocuente respecto de esas diferencias ideológicas.

Los tres escritores recibieron 1000 pesos $^{4}$ por el libro y, como era frecuente entonces, los autores antologados no cobraron nada ni tampoco los antólogos en el futuro.

Bioy — para quien, ingenuamente, la ausencia del pago de los derechos de autor era responsabilidad suya (Bioy Casares 2006, 1558) y no de los editores— refiere su desconocimiento del tema hasta la colección «El séptimo círculo» de Emecé y la ignorancia absoluta de Borges sobre cualquier tipo de contrato legal hasta su muerte.

Bioy recuerda que

...la Antología alcanzó un éxito de estima que nos animó a emprender otras. La segunda y última de aquella serie fue la Antología poética, llamada así por los editores, que prefirieron la eufonía a la corrección. El libro no tuvo buena fortuna. (...) Años después propusimos al mismo editor, López Llausàs, una segunda Antología de la literatura fantástica. Nos dijo que la primera comercialmente había resultado un fracaso y no aceptó nuestra propuesta. Años después me invitó a verlo para convencerme que Silvina comprara acciones de la editorial. Me dijo entonces que todos los libros, incluso nuestra Antología de la literatura fantástica, se vendían muy bien. No creo que eso revelara deshonestidad. Simplemente, cuando le propuse el nuevo volumen de literatura fantástica, él tuvo prudencia de comprador y cuando ofreció las acciones tenía optimismo de vendedor. Yo aconsejé a Silvina que rechazara la oferta, no por prudencia de comprador, sino porque pensé siempre que un escritor no debe vivir de las rentas de libros de sus colegas. (Bioy Casares, 1994:88)

La longevidad la Antología de la literatura fantástica fue enorme. Sudamericana la volvió a editar (ampliada) en 1965 y hasta 2008 continuó publicándose tanto en España como en la Argentina con el sello Edhasa. Los derechos de Borges como los de Bioy Casares pertenecen ahora a Penguin Random House. 


\section{El origen}

En el prólogo de la Antología de 1940 se expone:

Una noche de 1937 hablábamos de literatura fantástica, discutíamos los cuentos que nos parecían mejores; uno de nosotros dijo que si los reuniéramos y agregáramos los fragmentos del mismo caracter anotados en nuestros cuadernos, obtendríamos un buen libro. Compusimos este libro.

El fragmento recuerda, casi copia, la atmósfera inicial de Otra vuelta de tuerca de Henry James donde caballeros y una dama intercambian opiniones sobre historias siniestras que son el preludio de la historia que después cuenta el relato de James.

También en la Antología, el acto de dirimir entre piezas diversas del género fantástico y la búsqueda de los fragmentos también fantásticos «anotados en nuestros cuadernos» son los preliminares de lo que llega luego, una escritura que se percibe como homogénea. La memoria del lector corrobora la hipótesis: en el recuerdo sobresalen ciertos textos pero lo preside una continuidad de orden estético, porque, a pesar de que los relatos fueron escritos en lenguas y épocas diversas, comparten la forma verbal del prólogo y hasta parecen una impersonal y extensa oratio obliqua de esa voz.

Además, la sucesión de textos ingleses, franceses, italianos, chinos, árabes o castellanos revela algo que excede el límite de lo fantástico: la escritura traduce, incorpora, reproduce, altera, recorta y articula dando significados diferentes o nuevos a cualquier plano de lo literario. En verdad, esas transformaciones son lo literario.

Muy remotamente, Juan Ruiz escribió el Libro del buen amor tomando la poesía erótica de Ovidio fundida con una comedia latina del siglo X, Pamphilus de amore, de la que cambió los nombres de lugar y de los personajes para que fueran españoles. No sólo hubo una apropiación del Pamphilus — también lo citaron y usaron Chaucer y Boccaccio-: tampoco pudo ser leído ya como texto medieval.

El ejemplo ilustre descubre lo que la Antología muestra: los escritos ingleses, franceses, italianos, chinos, árabes o castellanos encadenados como parte de una serie unitaria toman un nuevo sentido y, al mismo tiempo, los textos en castellano, ${ }^{5}$ que parecen casi una enumeración caótica [María Luisa Bombal, Jorge Luis Borges, Santiago Dabove, Macedonio Fernández, Don Juan Manuel, Ramón Gómez de la Serna, Leopoldo Lugones, Manuel Peyrou, José Zorrilla, Arturo Cancela, Pilar de Lusarreta], deben ser leídos de otra manera, incluso aquellos — como el de la amiga de Borges, María Luisa Bombal, probablemente más admirada que talentosa- que después desaparecieron.

La proporción fue desde luego irrelevante. La abundancia de autores ingleses (o recibidos a través de la lengua inglesa) sí resulta significativa. Más que enfatizar a ciertos escritores parece defenderse la creación de otro canon: no la literatura realista española que seguía siendo un modelo; tampoco la tradición francesa casi hegemónica en el Río de la Plata sobre todo en su versión más borrosa y que desde el siglo XIX se fue considerando un ejemplo de refinamiento y de perfección. Fueron excepciones la inclusión de Ramón Gómez de la Serna («el más inventivo de los escritores españoles») y Jean Cocteau del que Borges pensaba que era un «buen poeta» y al que también Bioy recordaba como cineasta.

La operación crítica, por tanto, fue doble: las traducciones de textos completos o fragmentarios mostraban por sí mismas una manera de entender, escrutar y 
rearmar la serie literaria de lo fantástico; las traducciones, los textos originales, los apócrifos (escritos en realidad por Borges y Bioy) y los relatos que escapaban de una definición tradicional de esa nueva forma de ficción (porque trataban sobre escritores), creaban otra serie paralela, más compleja. No una historia antológica de lo fantástico, como las muchas que vinieron después: una historia de la escritura de lo fantástico. La Antología contaba historias, como observaron Umberto Eco y Bioy Casares, que contaban cómo se escribe una historia.

\section{La traducción}

Bioy identificó como propias (y de Borges) algunas traducciones: «El cuento más hermoso del mundo» de Kipling, «Enoch Soames» de Max Beerbohm, «Sredni Vasthar» de Saki, "Donde su fuego nunca se apaga» de May Sinclair, «El caso del difunto Mr. Elvesham» de Wells y las piezas dramáticas «Una noche en la taberna» de Lord Dunsany, «Donde está marcada la cruz» de O’Neill, «La pata de mono» de W. W. Jacobs. Añadió en otro lugar la traducción de Swedenborg, Poe, Villiers de L'Isle-Adam, también junto con Borges. La edición ampliada de 1965 incorporó algunos relatos de Cuentos breves y extraordinarios (1953) que habían hecho en los años cincuenta y es verosímil que, salvo excepciones, el resto de los textos, por la semejanza del estilo, tenga la misma autoría. Es decir, de Borges y Bioy porque ninguno de los dos mencionó la participación de Silvina Ocampo ni de nadie más.

La Antología fue el primer trabajo largo de traducción compartida, precedido y seguido de muchas colaboraciones, ediciones y reediciones: traducciones para Sur; una segunda antología fantástica que no se hizo; la sección Museo de las revistas Destiempo (1936) y Los Anales de Buenos Aires (1946, 1947); los volúmenes de El Séptimo Círculo, Cuentos breves y extraordinarios (1955, 1967, 1976); El libro del cielo y el infierno (1960); Los mejores cuentos policiales, primera y segunda serie (1943, 1947, 1951, 1952, 1956, 1962, 1965, 1967, 1976); Antología de la literatura fantástica, segunda edición ampliada $(1965,1967,1976)$.

El ejercicio de la traducción se combinó en esos largos años con la redacción de solapas o contratapas, con la escritura de las extraordinarias derivaciones de Bustos Domecq y con el ejercicio literario del género «apócrifo». Por ejemplo: «Después de comer, con Borges redactamos una contratapa para Brat Farrar de Josephine Tey, un libro que ninguno de los dos ha leído y del que no sabemos nada; ni siquiera el jacket inglés: inventamos un crítico y su juicio». En opinión del experto imaginario, Farrel du Bosc:

Las novelas de Josephine Tey sobresalen por su educada ironía, por su agudo conocimiento del alma humana y por el acento trágico. El manejo de la expectativa es, en todas ellas, magistral y la trama del enigma, impecable. Ninguna de ellas nos parece mejor que Brat Farrar. (Bioy Casares, 2006:73)

O también: 
Del Mabinogion traducimos o parafraseamos para la antología de cuentos breves la historia de los dos reyes que juegan al ajedrez mientras sus ejércitos combaten (y la suerte del combate depende de la suerte en el juego). La historia del sitio de Madagascar y la reina y el pueblo que seguían con más interés un ajedrez que las vicisitudes de las tropas que saqué de un irrecuperable Times Literary Suplement, la atribuimos a Celestino Palomeque, (Cabotaje en Mozambique, Porto Alegre, s. d.), en la seguridad de que nadie advertirá ninguna anomalía métrica. (80)

El cotejo de los textos de la Antología con originales reales revela numerosas elipsis y desviaciones, sin duda, voluntarias. Detalle que percibe el lector especializado y que escapa de la visión del common reader como corresponde a la distribución final de los honores poéticos previstos para quien cumple con el mero deber de la lectura placentera.

En 1981, cuando la Antología de la literatura fantástica se tradujo al italiano, Borges le comentó a Bioy con perplejidad: «No tradujeron nuestra antología: buscaron las fuentes y tradujeron. Procedieron con seriedad, a costa del lector, desde luego». Y añadió: «No debieron elegir un libro de autores que se distinguen por sus transcripciones y citas infieles» (Bioy Casares, 2006:1561). Curiosamente, la versión norteamericana de la obra [Viking Penguin, 1988] es todavía más infiel que la «infidelidad creadora» de los antólogos: no figuran los autores ni los textos imaginarios y su ausencia fue ocupada por escritores existentes como Ambrose Bierce y Walter de la Mare, especialmente excluidos en el prólogo de Bioy, más J. G. Ballard, Evelyn Waugh, Voltaire, Edith Wharton, Mary Wollstonecraft Shelley, que no figuran en ninguna otra recopilación de sus autores. La obra tiene un prólogo de Ursula K. Le Guin, traducciones de Anthony Kerrigan, uno de los primeros y excelentes artífices de las versiones de Borges en inglés, y resulta, por su contenido, bastante misteriosa.

\section{El manual de instrucciones}

En la Argentina de 1940 (y casi siempre después) existían comunidades de lectores que subsistían fuera de la industria editorial y cultural, supervivencia de lo que Bourdieu nombró metafórica (y no muy elogiosamente) actividades de art pur, propias de las sociedades precapitalistas. Las obras que compilaron Borges y Bioy, y también la Antología, se inscriben en este escenario (en realidad, podría pensarse que antes de los años setenta toda la literatura argentina pertenecía a ese escenario, porque el sistema de autorizaciones se regía por las relaciones personales sin las mediaciones de la industria editorial o de los medios de comunicación y sus relativas supercherías).

En el prólogo de 1940 se hablaba de «nuestros cuadernos» y recorriendo la notable extensión de los textos y autores antologados «desde» este libro, debería decirse que estas obras contenían «nuestras bibliotecas». Se trata de algo curioso. Tres o dos escritores, uno de ellos considerado entre los mayores del siglo $\mathrm{xx}$, dedicando muchísimo tiempo de su vida literaria a elegir, considerar, traducir y editar fragmentos para ponerlos a disposición de los lectores. Pacto de lectura que incluía una donación — qué y cómo leían los autores - y un manual de uso cuyas instrucciones estaban en el propio texto. Aunque era también posible, el libro solicitaba algo 
más que una lectura literal: los fragmentos y los cuentos, discretamente infieles, proponían una revisión de la tradición literaria cuyo epígrafe más apropiado sería: «No incurran en el purismo. Alteren y transformen», frases que clausuran el relato "Gradus ad parnasum» (Crónicas de Bustos Domecq, 1967).

Borges y Bioy opinaron, como dice Bioy en 1978 (en el Borges de Bioy), que la Antología sirvió para enseñar «a inventar y a contar argumentos». Y también señaló:

Fue una ocupación gratísima, emprendida sin duda por el afán de hacer que los lectores compartieran nuestro deslumbramiento por ciertos textos. Ese fue el impulso que nos llevó a componer el libro, pero mientras lo componíamos alguna vez comentamos que serviría para convencer a los escritores argentinos del encanto y los méritos de las historias que cuentan historias. (1994)

El efecto multiplicador de esta donación no necesita mayores comentarios: la segunda edición (1965) incorporaba, como la segunda parte de Don Quijote, fundamentales ejemplos de que los lectores habían leído la primera parte.

\section{The Future}

Francisco Porrúa (que sustituyó a Cèsar August Jordana como asesor de Sudamericana) le propuso a Julio Cortázar la corrección de la Antología del cuento fantástico de Roger Caillois que la editorial de Buenos Aires iba a publicar en 1967 y que Roger Caillois había compilado para corregir los «defectos» (dicho discretamente por el propio Caillois) de la Antología de Borges, Bioy y Silvina Ocampo.

El 19 de agosto de 1960 Cortázar contestó a Porrúa:

La antología de Caillois podría publicarse, me parece, pero cambiándola bastante. Por supuesto «La pata de mono» tiene que volar, y en cambio habría que reunir el sector surrealista de lo fantástico, que Caillois desdeña por una cuestión de partipris. ¿Estaría él dispuesto a esos cambios? He aquí algunos nombres necesarios para el enfoque surrealista: Leonora Carrington ("Conejos blancos», por ejemplo), André Pieyre de Mandiargues... Si usted decide publicarla, cuente conmigo para buscar buenos cuentos fantásticos. (...) ¿ ¿Ha pensado usted en la posibilidad de hacer alguna vez una antología de textos de locos? Aquí el género tiene grandes representantes, y yo por mi parte colecciono maravillas desde hace años. (Cortázar, 2000:427-428)

Unos meses más tarde, ya el año siguiente, el 20 de abril de 1961 continuó:

Sobre la antología, no me he olvidado de lo que hablamos, y me sigue gustando la idea de colaborar. Muchas gracias por querer que sea $m i$ antología, en realidad la haremos usted y yo, y para mostrarle mi interés; aquí van ya unas ideas. Me parece que no hay que hacer otra antología de la literatura fantástica, primero porque como usted me dice, Sudamericana va a publicar la de Caillois, y eso saturará a los lectores, que al fin y al cabo no son tantos. Se me ocurre que sería más divertido y original hacer algo así como una «Antología de la literatura insólita» [Un asterisco corrige: O, mejor, "Panorama».] Esto nos daría una enorme latitud, porque si bien el grueso del libro estaría dado por cuentos fantásticos, podríamos agregar 
muchas otras cosas curiosas y fascinantes. Textos de locos, por ejemplo, y pasajes de ciertas filosofías (Zen, taoísta) en los que hay cosas extraordinarias, podríamos incorporar textos de un cierto humor negro en la línea de Ionesco y sobre todo Schwitters (¿conoce «La lotería del jardín zoológico»?) y también Alphonse Allais; podríamos dar o tres cuentos breves de surrealistas como Leonora Carrington (o sea ese lado de lo fantástico que los espíritus geométricos como Borges o Caillois detestan o dejan de lado), también se me ocurren (...) recetas de cocina de Edward Lear, pasajes de Jarry. (...) Pienso incluso en (...) cartoons extraordinarios, para quitarle al libro todo aire de «importancia» y darle por contragolpe su verdadera importancia. (437-438)

El libro del que hablaba Cortázar no se hizo, aunque, en cierto modo, el libro existió. La propuesta repetía el índice de la Antología del humor negro de Breton y las colecciones de l'art brut de Jean Dubuffet, no muy literarias, porquecomo reveló la colección más relevante de Écrits bruts de Michel Thévoz, las perturbaciones psíquicas son agramaticales y tristemente monótonas. Los materiales dieron forma a La vuelta al día en 80 mundos (1967) y también aparecen citados en Rayuela (1963) donde un personaje desprestigia todo lo anterior diciendo: «esas son las soluciones fáciles, cuentos fantásticos para antologías».

Bioy cuenta un episodio final que ilumina una vez más la capacidad multiplicadora de aquella donación de 1940. En 1979 recibieron la propuesta de compilar una nueva Antología de la literatura fantástica:

Para este Handbook of Fantastic Literature, Borges y Bioy escribieron un prólogo y prepararon un índice. En marzo de 1980 Alberto Manguel les comunicó que el libro sería editado por Lester \& Orpen Dennys de Toronto, a principios de 1981. Finalmente, en 1983, Manguel publicó en dicha editorial, bajo su exclusiva autoría, la antología Black Water. (Bioy Casares, 2006:1528)

El volumen, que tiene varias ediciones, reproduce en gran parte la lista de autores de la Antología inicial y también varios de aquellos relatos. Completan el índice otros escritores de la curiosa versión norteamericana mencionada antes. En ambos casos, las novedades son escritores que el presente considera «encantadores y brillantes» o, con palabras de Pierre Bourdieu, nacidos de los bombos mutuos.

\section{Final}

Las vanguardias hicieron del fragmento y de la adulteración un elemento decisivo del lenguaje artístico, aquella visión - moderna todavía en 1940 - convivía en la Antología con una concepción formalista - la literatura es una historia de formas no de sujetos- de la que este volumen es una representación. Si la colección hubiera sido una sucesión de modelos propuestos a la imitación, no hubiera sobrevivido. Muchísimas antologías copiaron los textos y los autores y nunca superaron a este libro. La razón de la posteridad reside en la combinación de paradigmas narrativos, los trozos atribuidos a autores imaginarios y la fragmentación como método. No hubiera sido tan importante si todo hubiera sido «verdadero». 
Bioy recordó en Borges, la felicidad de aquellos días en los que leyeron y escribieron tantas cosas juntos. En esa obra narrativa - la más extraordinaria de la literatura argentina - la escena del trabajo en común va diluyéndose en melancolía. Ciertas amistades sólo ocurren una vez; también ciertos libros, como el que terminamos de comentar.

\section{Notas}

${ }^{1}$ Savinio justamente ironiza sobre el extraño fenómeno físico que sufrió Baudelaire cuyo parecido con Edgar Allan Poe terminó por resultar extraordinario.

${ }^{2}$ Las informaciones proceden de Gabriela dalla Corte y Fabio Expósito: «Mercado del libro y empresas editoriales entre el Centenario de las Independencias y la Guerra Civil espańola: la editorial Sudamericana», en Revista Complutense de Historia de América, 2010, 36, 257-289.

${ }^{3}$ Jordana cruzó los Pirineos al terminar la guerra civil. Se exilió en Francia y junto con otros escritores catalanes llegó a Chile en 1940 en el Florida. Trabajó en Buenos Aires como editor, traductor y difusor de la cultura catalana en el Río de la Plata. Una de sus obras literarias El món de Joan Ferrer (1971) describe la vida literaria y el exilio en Buenos Aires.

${ }^{4}$ La cantidad era exigua pero no exageradamente comparada con los 700 pesos que pagó Losada por la primera edición de El Aleph en 1949 o los 2500 pesos que ofreció Emecé por Evaristo Carriego en 1955, el tercer volumen de las Obras completas.

${ }^{5}$ La lista de la reedición de 1965, respetando también el orden que encuentra el lector es: José Bianco, Adolfo Bioy Casares, Jorge Luis Borges, Delia Ingenieros, Arturo Cancela, Pilar de Lusarreta, Julio Cortázar, Santiago Dabove, Macedonio Fernández, Elena Garro, Ramón Gómez de la Serna, Don Juan Manuel, Leopoldo Lugones, H. A. Murena, Silvina Ocampo, Carlos Peralta, Manuel Peyrou, Juan Rodolfo Wilcock, José Zorrilla.

\section{Referencias bibliográficas}

Balderston, D. (2004). La Antología de la literatura fantástica y sus alrededores. En El oficio se afirma. Historia critica de la literatura argentina, Tomo 9 (pp. 217-227). Buenos Aires: Emecé.

Borges J.L., Bioy Casares, A. y Ocampo, S. (1940). Antología de la literatura fantástica. Buenos Aires: Sudamericana.

Bioy Casares, A. (2006). Borges. Barcelona: Destino. (1994). Memorias. Barcelona: Tusquets.

(17 de abril de 1994). Fragmento de memorias (selección de Marcelo Pichon Rivière), Clarín, Buenos Aires, Suplemento de cultura. Buonocore, D. (1944). Libreros, editores e impresores de Buenos Aires. Buenos Aires: El Ateneo.

Cortázar, J. (2000). Cartas (1937-183). Buenos Aires: Alfaguara. 3 vols. 
Costa, W. (2009). Las traducciones de la Antología de la literatura fantástica de Borges, Bioy Casares y Silvina Ocampo. Cuadernos Americanos, Nueva Época, 3(129), 159-167.

Dalla Corte, G.; Espósito, F. (2010). Mercado del libro y empresas editoriales entre el Centenario de las Independencias y la Guerra Civil española: la editorial Sudamericana, Revista Complutense de Historia de América, 36 [en línea]. http://revistas.ucm.es/index.php/RCHA/article/ view/RCHA1010110257A

Diego, J.L. DE (Dir.) (2006). Editores y politicas editoriales en Argentina. 1880-2000. Buenos Aires: Fondo de Cultura Económica.

Martínez Martín, J. (Dir.) (2001). Historia de la edición en España (1836-1936). Madrid: Marcial Pons.

(Dir.) (2014). Historia de la edición en España (1939-1975).

Madrid: Marcial Pons.

Ocampo, V. (1966). Vida de la revista Sur. Sur. 303, 304, 305 (noviembre 1966, abril 1967).

(1999). Correspondencia Victoria Ocampo-Roger Caillois (19391978). (Prólogo, selección y notas de Odile Felgine con la colaboración de Laura Ayerza de Castilho). Buenos Aires: Sudamericana.

Rest, J. (1976). Reflexiones de un traductor. Sur: Problemas de la traducción. 338-339 (enero-diciembre de 1976), 191-203.

Rivera, J.B. (1980-1986). Apogeo y crisis de la industria del libro: 1955-1970. Capitulo. Historia de la literatura argentina. 4: Los proyectos de vanguardia. Buenos Aires: Centro Editor de América Latina.

SAítTA, S. (Dir.) (2004). El oficio se afirma. En Jitrik, N. de (Dir.) Historia crítica de la literatura argentina. Tomo 9. Buenos Aires: Emecé.

\section{Gargatagli, Anna}

